\title{
The development of luminescent solar concentrator-based photomicroreactors: a cheap reactor enabling efficient solar-powered photochemistry
}

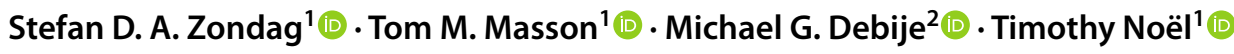

Received: 28 September 2021 / Accepted: 27 October 2021 / Published online: 12 November 2021

(c) The Author(s) 2021

\begin{abstract}
Sunlight strikes our planet every day with more energy than we consume in an entire year. Therefore, many researchers have explored ways to efficiently harvest and use sunlight energy for the activation of organic molecules. However, implementation of this energy source in the large-scale production of fine chemicals has been mostly neglected. The use of solar energy for chemical transformations suffers from potential drawbacks including scattering, reflections, cloud shading and poor matches between the solar emission and absorption characteristics of the photochemical reaction. In this account, we provide an overview of our efforts to overcome these issues through the development of Luminescent Solar Concentratorbased PhotoMicroreactors (LSC-PM). Such reactors can efficiently convert solar energy with a broad spectral distribution to concentrated and wavelength-shifted irradiation which matches the absorption maximum of the photocatalyst. Hence, the use of these conceptually new photomicroreactors provides an increased solar light harvesting capacity, enabling efficient solar-powered photochemistry.
\end{abstract}

This review is dedicated to Prof. Angelo Albini (University of Pavia, Italy) on the occasion of his 75 th birthday.

Stefan D. A. Zondag and Tom M. Masson have contributed equally to this work.

Extended author information available on the last page of the article 


\section{Graphical abstract}

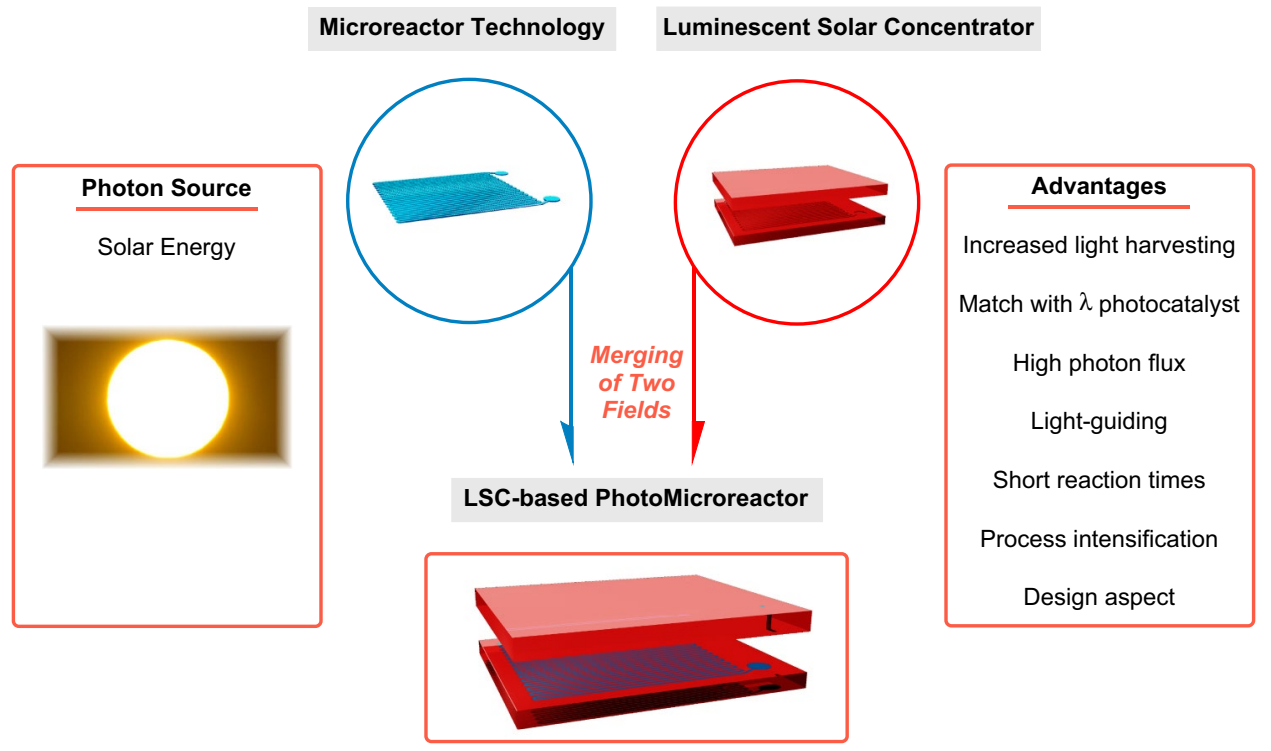

Keywords Solar photochemistry $\cdot$ Microreactor $\cdot$ Luminescent solar concentrators $\cdot$ Automation $\cdot$ Scale-up $\cdot$ Ray tracing simulations

\section{Introduction}

"The essential preliminary of all chemical changes by radiations is absorption." This first law of photochemistry (Grotthuss-Draper law) formulated by both Draper and Grotthuss independently in the nineteenth century remains true to this day $[1,2]$. Although succinct, the statement describes most of the limitations faced in the field of photochemistry. In other words, how can one maximize the amount of light absorbed by the reaction mixture and thus be productively used for driving chemical transformations? To address this challenge, researchers in synthetic organic chemistry have dramatically increased their efforts over the past years, unlocking the full potential of photochemistry by developing photocatalytic variants which can be used across the entire solar spectrum [3-8]. This newly regained interest in the field was further stimulated by the access to low cost, energy efficient, high intensity and durable light sources (e.g. lightemitting diode (LED) technology) [9] and the development of scalable reactor technology (e.g. continuous-flow microreactor) [10-16]. Having access to affordable light sources and superior photochemical reactors, nothing was holding back chemists from implementing photochemical transformations in their work en route to complex and biologicallyactive organic molecules [17-19].

Another key factor behind this enthusiasm lies in the quest for a more sustainable and environmentally-friendly chemical industry [20]. In accordance with the principles of green chemistry, photochemical processes can contribute to a more sustainable production of chemicals [21-23]. Waste reduction can be achieved as photons are regarded as renewable and traceless reagents [24-26], and the generally mild reaction conditions allow for safer processes. A significant aspect of photochemistry that ties in with the green chemistry concepts is visible-light photoredox catalysis [27, 28], since this enables the use of sunlight as a renewable and perennial light source $[29,30]$. To intensify solar photochemistry, effective harvesting of sunlight in combination with continuous-flow technology is crucial to unlock its full potential [10, 12, 29, 31, 32]. A wide array of different solar reactors has been developed over the years, ranging in sizes and light concentrating abilities [31, 33, 34]. Examples of non- or low-concentrating designs are flatbed reactors [35] and compound parabolic collectors [36, 37], whereas reactors, such as parabolic troughs $[38,39]$, parabolic dish solar concentrators [40] and solar furnaces [41, 42] are designed to focus and concentrate solar light to the reactor surface. These concentrating designs excel in intensifying solar irradiation using mirrors and reflectors but suffer from other drawbacks: they generally require large collection areas, encounter overheating issues due to the increased solar intensity and require relatively clear weather conditions for operation due to the restricted use of only direct incident light. This imposes the need to use solar trackers 
and limits the terrestrial locations where this technology can be deployed. The non-concentrating designs, such as the flatbed reactor, are generally operated at a specific tilt angle, without the need for solar tracking because they can make use of diffuse as well as direct light. However, since solar light is not concentrated, the light intensity for such devices cannot be increased further to match those of the concentrating devices.

Therefore, the Holy Grail for the productive use of solar irradiation for chemical production would be a device that can efficiently use both the direct and diffuse portions of incident solar irradiation and effectively concentrate the light without the need of solar tracking. Although technological advancements can contribute to the development of such a device, a possible solution lies within the field of material sciences, where Luminescent Solar Concentrators have been guiding light for more than 40 years [43] In this review, we provide an overview of our efforts to develop the concept of the Luminescent Solar Concentrator-PhotoMicroreactor (LSC-PM), which can harvest solar energy to promote lightdriven photochemical transformations.

\section{Luminescent solar concentrators}

In the late $70 \mathrm{~s}$, Luminescent Solar Concentrators (LSCs) were introduced to reduce the cost of solar electricity [44-46]. Combining luminescent media to down-convert and guide light towards a photovoltaic (PV) cell allowed enhancement in the electrical production while keeping the size of PV cells, that were expensive to manufacture, small. While the costs of the technology could not compete with the low prices of electricity produced from oil at the time, the depletion of fossil fuels pushed researchers to improve the LSC technology for wider implementation [43]. The aesthetics and the robustness of the technology granted the LSCs an advantage against conventional PV panels in urban areas. Hence, the LSC design has been implemented in various environments, such as smart windows [47], noise barriers [48], bike stations [49] and in horticulture [50]. Their ability to gather both diffuse and direct light is a characteristic that sets LSCs apart from competitive technologies and allows for its implementation in fluctuating or low light intensity environments.

LSCs are typically made of inexpensive materials, such as plastics containing fluorescent dyes or glass covered with a luminescent coatings [43]. The incoming solar irradiation is absorbed by the luminophores and a significant fraction is re-emitted inside the material. The emitted radiation is guided by total internal reflection towards the edge(s) of the material. According to Snell's law, when light travels from a high refractive index media to a lower refractive index, a critical angle can be determined ( $\alpha=\sin ^{-1}\left(n^{-1}\right)$, where $n$ is the refractive index of the host material) [43]. If the incident ray reaches the interface with a greater angle, it will be internally reflected and will not escape the medium (Fig. 1). For a typical LSC with a refractive index around 1.5 , it means that approximately $75 \%$ of the photons will be internally reflected and guided towards the edges of the material, where a PV cell is often located [43].

While LSCs have been widely studied and described for electricity production, their attractiveness expanded into other applications such as position sensors, H-production,
Fig. 1 Working principle of an LSC: (1) The solar radiation reaches the material. (2) The luminescent dye in the material absorbs the incoming radiation. The dye re-emits a down-shifted radiation in every direction. (3) The emitted radiation is guided towards the edge of the material to be collected with a photovoltaic cell

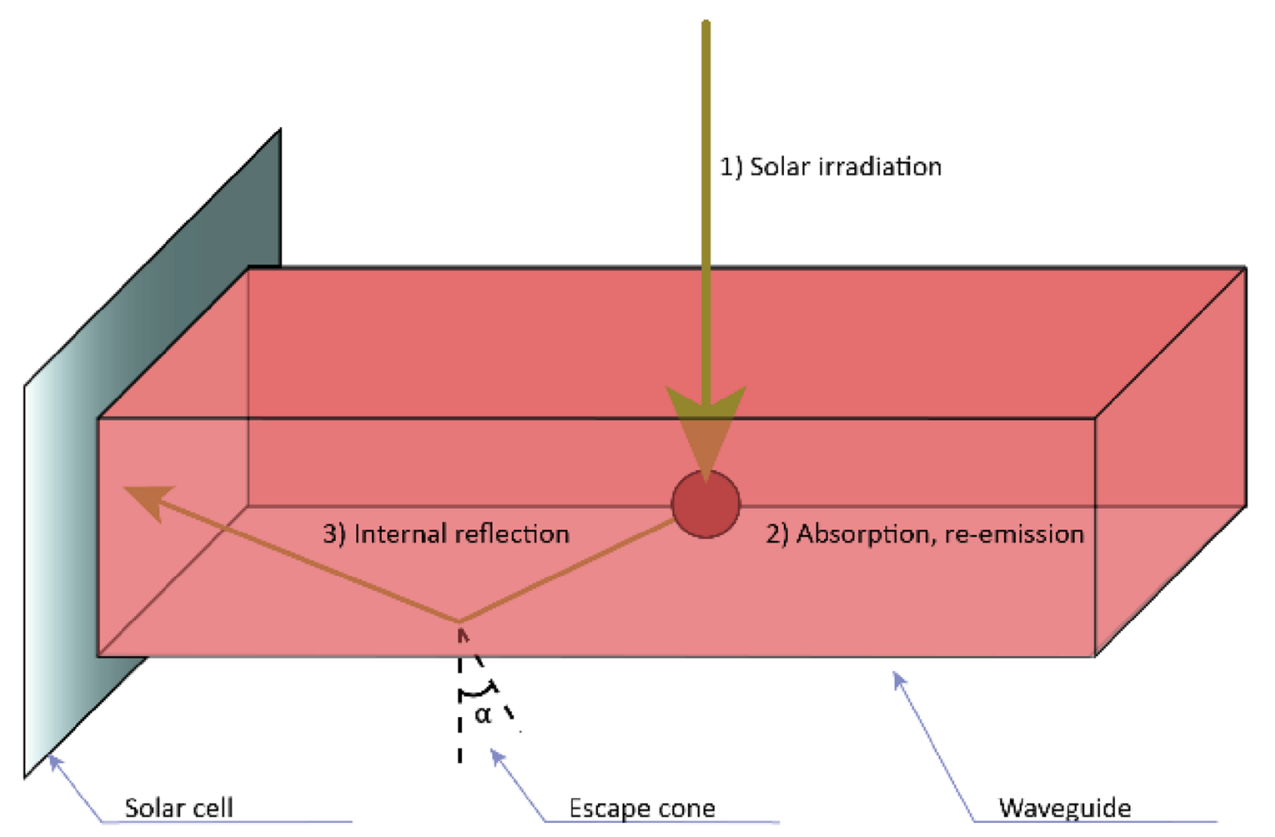


X-ray scintillators, algae production and LED-pumped luminescent concentrators [51,52].

\subsection{The genesis of the LSC-PM concept}

Inspired by the way natural tree leaves gather solar light [29], our groups imagined an LSC combined with microflow technologies to make use of this light gathering effect to power photochemical transformations (Fig. 2). Analogous to antenna's pigments guiding solar energy towards the chlorophyll reaction center [53], the luminescent dye, together with the LSC's internal reflective properties, focuses the photons towards the reaction channels. Thus, contrary to traditional LSC applications, the light trapped by the luminescent waveguide can be intercepted by the reaction mixture instead purely being focused towards the edges of the device.

Because of the reaction channel placement within this device, the path followed by emitted photons is inherently short, which allows the microreactor to minimize reabsorption losses from which the photovoltaic LSC technology suffers when light travels over larger distances [54]. This enables the doping of reactors with a higher dye loading without significantly increasing the reabsorption losses, improving the light harvesting even further. As the reaction kinetics of photochemical transformations are critically dependent on the number of photons, the increased photon flux reaching the reaction channels enhances the productivity of the solar reactor.

In addition to the light-guiding effect, the photon-absorbing luminescent dye re-emits radiation in a narrow wavelength range through fluorescence which, if judiciously chosen, overlaps the absorption band of the photocatalyst. This feature is unique for the LSC-PM and allows conversion of broad-spectral daylight into useful photons matching the intended application. In addition, a narrow spectral distribution could improve the overall reaction selectivity; for example, undesired wavelengths often cause degradation of the starting materials and/or products and normally need to be filtered out, leading to reduced energy efficiencies of the light source [55]. As a concrete example in our work, a $5 \times 5$ $\mathrm{cm}^{2}$ serpentine six-channel polydimethylsiloxane (PDMS) Luminescent Solar Concentrator Photo-Microreactor (LSCPM) was doped with a luminescent red dye, Lumogen Red 305 (LR305). This commercial dye absorbs visible wavelengths below $600 \mathrm{~nm}$ and re-emits around $654 \mathrm{~nm}$. This matches almost perfectly with the absorption maximum of Methylene Blue (MB), a commonly-used photocatalyst (see Fig. 3) [56].

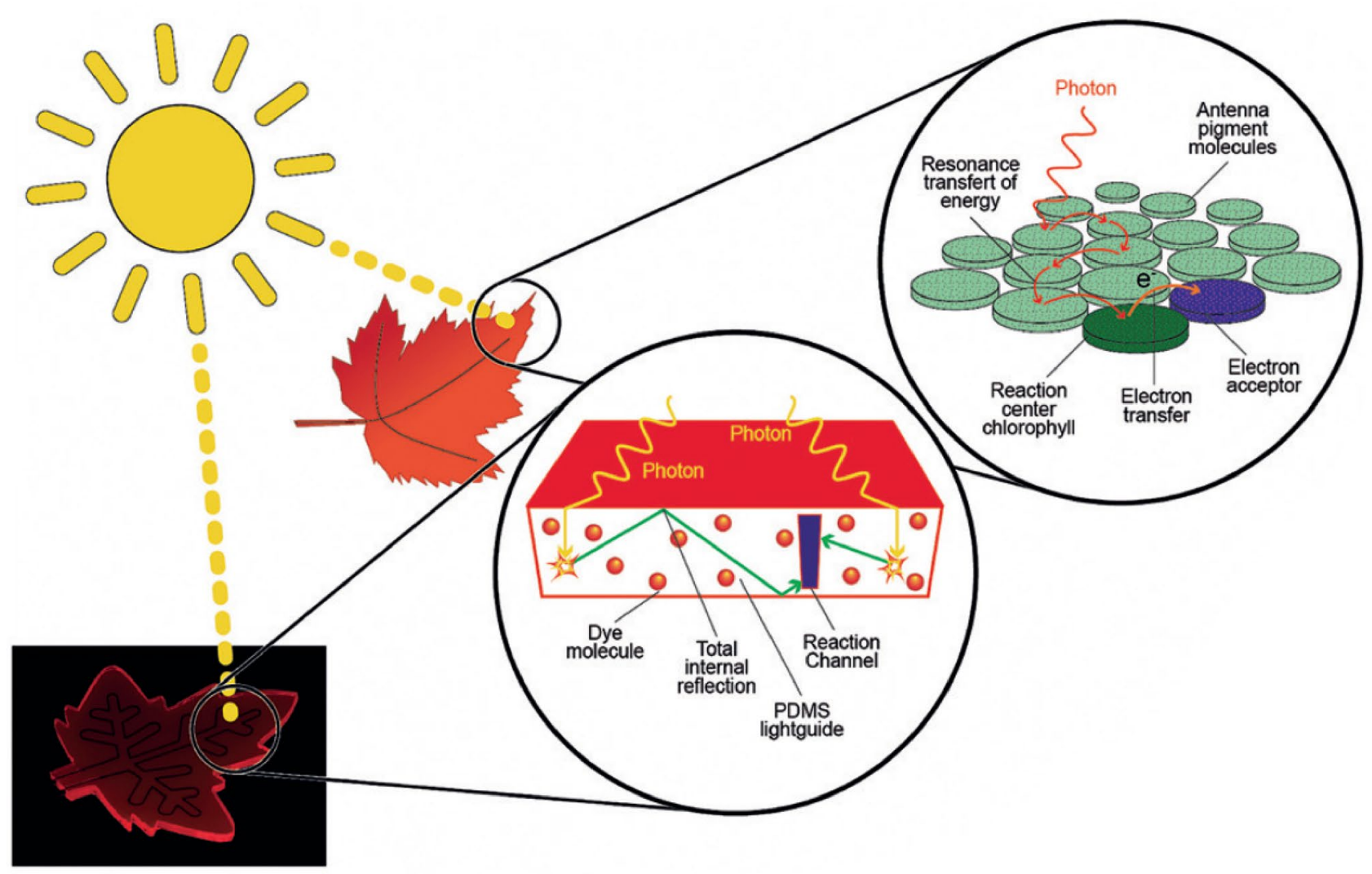

Fig. 2 Working principle of the leaf-inspired Luminescent Solar Concentrator Photo-Microreactor. The photons reaching the lightguide are directed via internal reflection to the reaction channel embedded into a PDMS-based LSC. Reprinted from [57] 
Fig. 3 Wavelength conversion scheme of the LR305/MB based LSC-PM. Reprinted from [57]

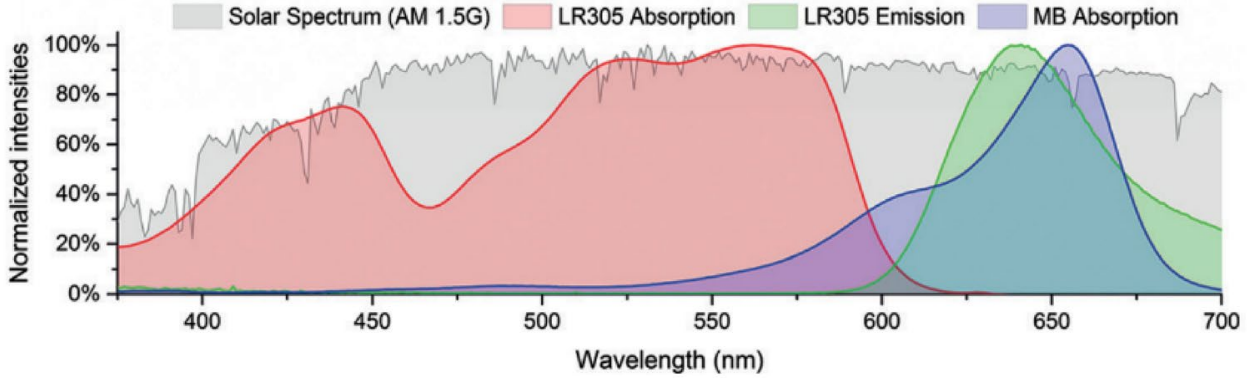

A

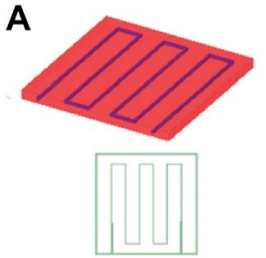

C
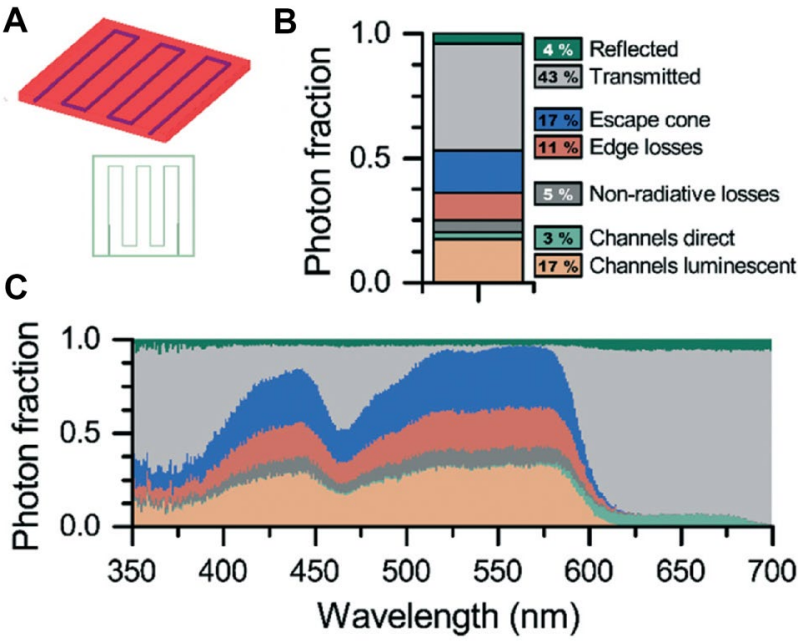

Fig. 4 A Model representation of the PDMS LSC-PM. Simulated relative contributions to the photon fates for the overall photon balance (B) and per transmitted wavelength (C). Reprinted from [58]

\subsection{Modelling and experimental validation of the LSC-PM concept}

To assess the efficiency of the LSC-PM, photochemical oxidations were performed under various reaction conditions. Comparing the performances of the LSC-PM against an identical, non-doped reactor highlighted the importance of including the dye as dopant. A kinetic enhancement up to 4.5 times could be realized for the singlet oxygen-mediated cycloaddition of 9,10-diphenylanthracene to yield the corresponding endoperoxide [57].

Encouraged by these first experimental results, a model was built which would offer a full understanding of the influence of several design parameters on the reactor performance. To this end, Monte Carlo ray-tracing was employed to gain insight into the photon balance of the system [58]. In these simulations, the solar spectrum was emulated by generating photons and randomly assigning their wavelengths based on an AM 1.5G probability distribution function. The generated photons irradiate a $3 \mathrm{D}$ representation of the $5 \times 5$ $\mathrm{cm}^{2}$ serpentine six-channel LSC-PM (see Fig. 4A), where the fate of each photon in the system was determined and the simulation results were experimentally validated with the previously described LSC-PM. The simulation results are shown in Fig. 4B, C, where the fraction of photons per final photon fate are given. Here the photons either reach the channels via direct irradiation or luminescence or are considered as losses (i.e. reflected, transmitted through the reactor, escaped from the reactors top/bottom/edges or nonradiative losses).

Optimization of various key LSC-PM design parameters was subsequently carried out in silico. Increasing the dye doping resulted in a decrease in transmittance through the reactor, while at the same time minimizing the loss of photons via reflection on the bottom reactor surface. Another interesting finding of these simulations was that a large fraction of the transmitted photons was $>600 \mathrm{~nm}$ wavelength (Fig. 4C), i.e. a region where the luminophore absorbs poorly or not at all, indicating that transmittance cannot be fully prevented with increasing dye doping. Importantly, being transparent for IR irradiation, the LSC-PM does not require additional cooling as compared to other solar reactors. In addition, the fraction of photons leaving the reactor via the edges (i.e. edge emission) increased at higher dye doping, exemplifying the increased light-guiding effect and decrease of transmittance. The edge emission losses found in small LSC-PM devices were expected to diminish for larger devices, since the photons would then need to travel over a larger average distance to reach the device edges with ever increasing probability of light re-absorption with increasing size. Several larger LSC-PM designs, up to $1 \mathrm{~m}^{2}$, were simulated with varying channel sizes and channel patterns. Of these simulations, the average path travelled by photons in the device were computed, concluding that the edge emission losses were indeed diminished and that the smallest inter-channel distances would minimize the relative nonradiative losses.

\subsection{Scale-up of the LSC-PM}

The $5 \times 5 \mathrm{~cm}^{2}$ LSC-PM design is, however, not suited for large-scale solar photochemistry. Scaling micro- and milliflow reactors in general, but even more so for photochemical applications, can be a challenging endeavour [11, 13, 59]. 


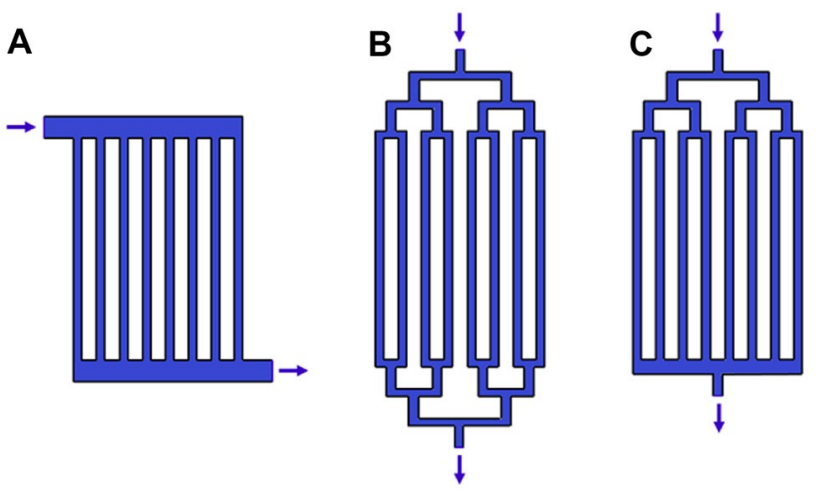

Fig. 5 The three distribution/collection configurations: A manifold/ manifold, $\mathbf{B}$ bifurcation/bifurcation and $\mathbf{C}$ bifurcation/manifold. Reprinted from [60]

A suitable strategy for scaling up the LSC-PMs is numbering up of the reactor channels: distribution of the inlet process stream over several parallel reactor channels [60]. For the application of this strategy to the LSC-PMs several different configurations for flow distribution and collection were considered to ensure equipartitioning of the flow (Fig. 5). It was found that a bifurcation design contributed to an overall larger pressure drop but could minimize the relative standard deviation of the average residence time of the parallel channels. The opposite effect was observed for the manifold chamber design. The increased pressure drops when the bifurcation design was used for both flow distribution and collection (Fig. 5B) resulted in leakages, but changing the collection design to the manifold chamber resolved this issue (Fig. 5C). This final design ensured equipartitioning of the flow, while maintaining an acceptable pressure drop. Interestingly, this same configuration was later used in the scale-up of another light-harvesting reactor design, i.e. the so-called Fluorescent Fluid Photochemical Microreactor. Instead of the luminophore being dispersed in the waveguide material as for the LSC-PM, this 3D-printed reactor design incorporates a fluorescent fluid in channels around the reactor channels [61, 62]. This enables the reactor to be used with different luminophore solutions and to replace this liquid after prolonged exposure to light.

Another crucial parameter for the parallel channels in the LSC-PM is the inter-channel spacing, as previously discussed for the ray-tracing simulations. For the scaling of an LSC-PM device, depending on the waveguide material and luminophore doping, an optimal inter-channel length can be determined. This optimum will be a trade-off between the increased sunlight-harvesting area, the reabsorption losses between the channels and the ratio between reaction area and sunlight-harvesting area.

\subsection{PMMA-based LSC-PM enable photocatalytic applications across the entire visible light spectrum}

Even though PDMS-based LSC-PM devices are easy and cheap to fabricate, some inherent shortcomings remained, limiting the versatility of the technology. The PDMS-based waveguide of the microreactor suffers from low-optical and chemical stabilities as most organic solvents tend to diffuse in PDMS, causing swelling, leaching of dye and degradation of the device [63]. To solve these issues, a second design was pursued based on the embedding of chemically resistant capillaries (e.g. Teflon-based capillaries) into a solid luminescent matrix (Fig. 6). Using commercially available inexpensive polymethylmethacrylate (PMMA)-based LSC plates was deemed to be a suitable alternative. PMMA has been studied extensively for electricity-producing LSCs, making them widely available in different colours and sizes [64-66].

Although the chemical stability of the reactor would be inherently improved with the design depicted in Fig. 6, it cannot be ignored that a new interfacial barrier is added for the light to travel through. To minimize the reflective effect at the interface between the LSC and the capillary, different high quality transparent capillaries were investigated, including perfluoroalkoxy alkane (PFA), ethylene trifluoroethylene (ETFE) and ethylene chlorotrifluoroethylene (ECTFE) with respective refractive indices of $1.34,1.40$ and 1.44 , respectively. By testing the reaction performances of the reactors containing capillaries with different configurations (e.g. PDMS waveguide with PFA capillaries, PMMA waveguide with ETFE capillaries), the team demonstrated that while the capillary material did not significantly affect the reaction performances, the waveguide material did have a pronounced effect [67]. Owing to the better surface smoothness and a higher refractive index of PMMA compared to PDMS (respectively 1.49 and 1.44 ) the light trapping properties were improved, translating to a $40 \%$ acceleration in reaction kinetics.
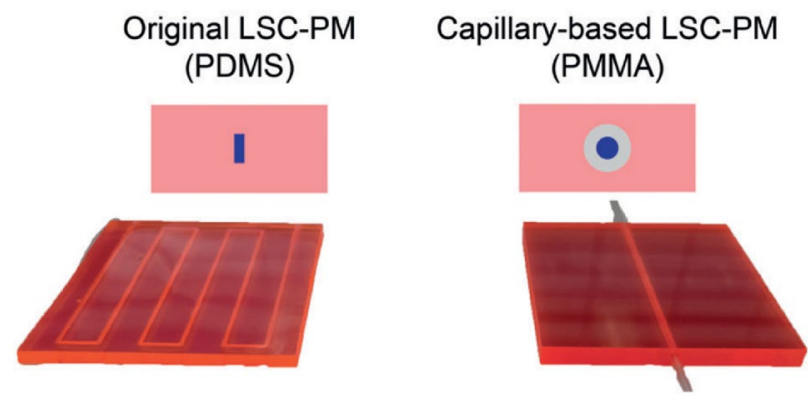

Fig. 6 Original channel design of the LSC-PM in a PDMS matrix (left) and the capillary-based design with PFA capillaries in a PMMA matrix (right). Reprinted from [67] 
Based on this new configuration, three differently coloured LSC-PMs were designed, enabling the luminophores to be matched to diverse photocatalytic transformations spanning the entire visible spectrum. To this end, in addition to the previously-established red LSC-PM design, both green and blue LSC-PMs were manufactured to match with other photocatalysts' absorption bands. After scaling up the concept up to a $30 \times 30 \mathrm{~cm}^{2}$ LSC-PM, several pharmaceutically-relevant transformations were performed to validate the designs (showcased in Fig. 7).

An improvement of up to 4.5 -fold could be seen when using both Eosin $\mathrm{Y}$ and Rose Bengal combined with the green LSC-PM. Since the LSC-PM design is intended for solar photochemical applications, they were tested under simulated sunlight. In this regard, the amount of light downconverted by the blue LSC-PM is inherently reduced due to the low amount of UV radiation in the solar spectrum.

Overall, this second generation LSC-PM combining PMMA-based waveguides and PFA capillaries addressed the main limitations of the original PDMS-based reactor. The PMMA provides strength, reproducibility and stiffness to the reactor, together with a high luminescent dye stability (3\% decrease in absorption for LR305 after 85 weeks) [68].

Although this design shows incredible promises, Zhao et al. raised concerns about mass transfer problems inside the LSC-PM capillaries. By packing glass or zircon beads inside the reaction channels, Zhao et al. managed to double the reaction rate of the photochemical oxidation of 9,10-diphenylanthracene (DPA) [69]. It is a simple yet efficient way to improve mixing inside the reaction channels while maintaining the high photon flux reaching the reaction mixture.

\section{Automated LSC-PMs}

The light-concentrating and -altering properties make the LSC-PM a promising tool for converting solar light into chemical bond energy via photocatalysis. Its ability to gather both direct and diffuse lights allow the device to perform chemical transformations both under intense sunlight and during cloudy weather. However, the number of photons reaching a photochemical device is far from constant throughout the day, which brings additional challenges to the LSC-PM project. For an LSC producing electricity, a varying irradiation means current fluctuations which can be handled if the energy is stored in batteries, for example. However, for a chemical reaction, a drop in light intensity leads to a decrease in conversion. This subsequently leads to need for additional purification steps that could have been avoided by using traditional light sources (e.g. LEDs). It is clear that a viable production system has to be able to cope with those naturally-occurring solar intensity fluctuations to maintain an optimal conversion output.

\subsection{Reliable production under variable weather conditions}

LSC technology offers a straightforward way to monitor photons reaching the reaction mixture: the light escaping
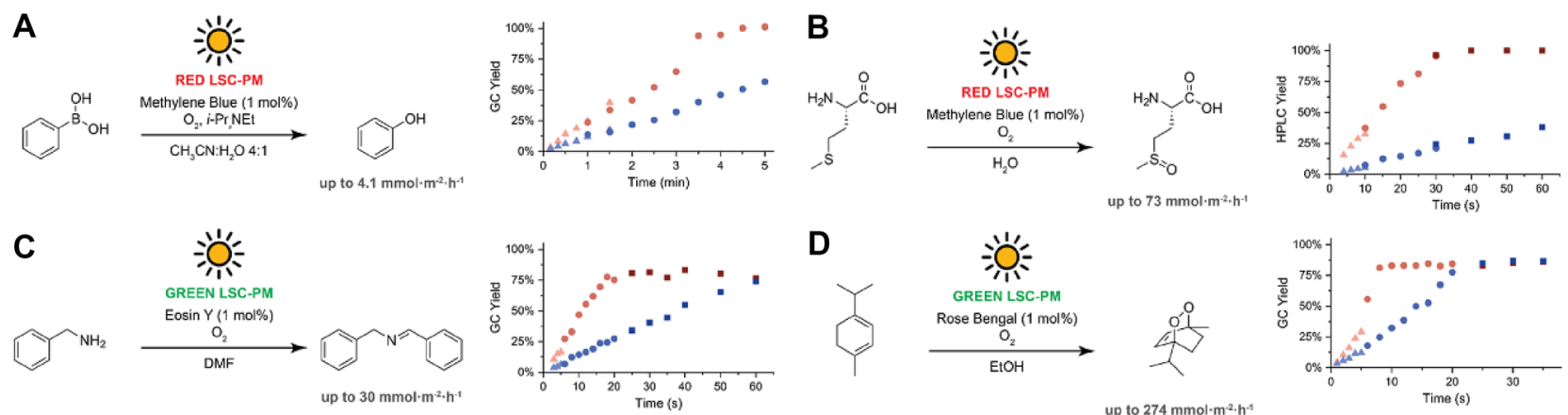

D
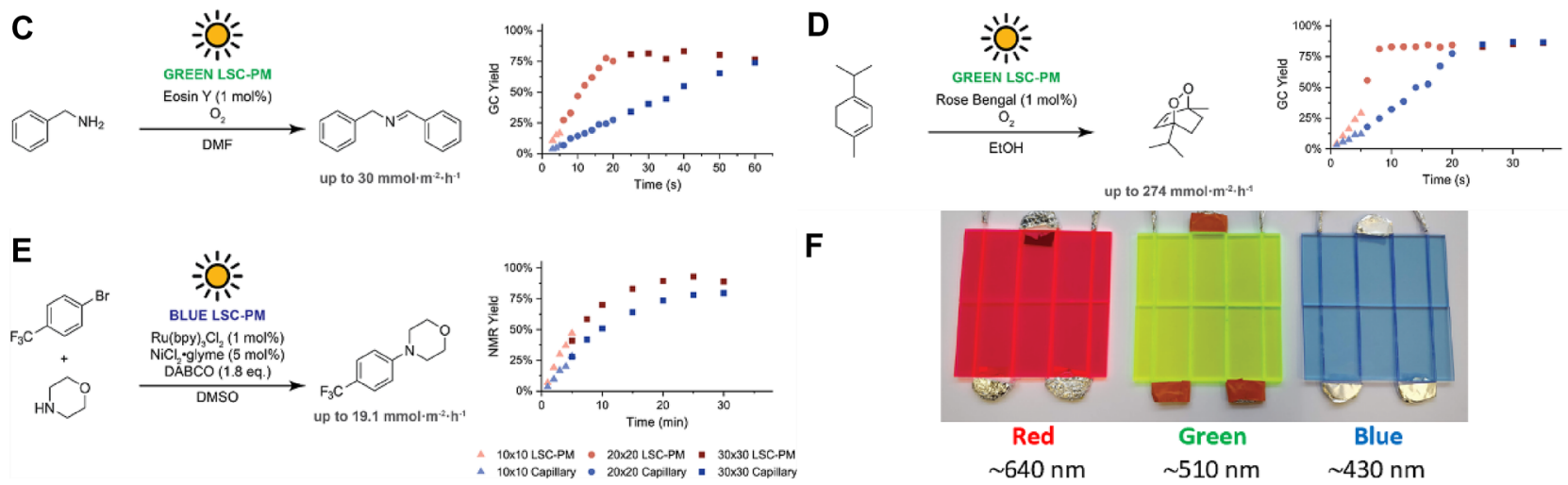

Fig. 7 Overview of the reactions performed in the PMMA-based LSC-PMs: A Hydroxylation of boronic acids, B Oxidation of (L)-methionine, C Benzylamine oxidation, D $\alpha$-Terpinene oxidation, E Morpholine arylation. F Photograph of LSC-PM containing 3 different dye dopants. Adapted from [67] 
from the edges of the material is proportional to the light guided towards the reaction channels. A careful calibration of the light intensity at the edges of the panel and the reaction conversion grants access to a feedforward control system. Such a control system could measure in real time the edge emission of the reactor and adapt the flow rate of the chemicals to ensure a constant conversion output.

The first control system was combined with a PDMS based LSC-PM. An Arduino microcontroller is used to adapt the liquid flow of a syringe pump and a light sensor records the edge emission from the LSC-PM (Fig. 8). This system ensures that a change in light intensity will result in a change in flow rate. By varying the residence time inside the reactor, a constant conversion can be maintained. An in-line UV-visible sensitive spectrophotometer was used to monitor the reaction conversion in real time and provided proof that, indeed, the reaction conversion remained stable.

To assess the performances of such a system, our group compared the conversion of two LSC-PMs performing a similar photo-transformation in parallel under sunlight. One reactor was controlled by the microcontroller system while the other one was operated at constant flow rate. With the control system, the conversion output remained between 86 and $93 \%$ while the non-regulated LSC-PM showed a conversion fluctuating between 55 and 97\% [70]. In this experiment, the targeted conversion was set at $90 \%$ to make sure that variations in conversion were rapidly noticed.

The properties and behaviour of such an automated control system for the PDMS-based LSC-PM operation under fluctuating light intensity were further investigated by Soares et al. [71]. A model of the reactor was made, based on the computational fluid dynamics (CFD) and kinetic studies of the photochemical oxidation of DPA. To realistically model this reaction, the reaction kinetics were studied for varying light intensities measured by the light sensor in the control setup. The rate constants of this reaction were then experimentally determined for the pseudo-first order reaction kinetics found at these different light intensity levels. These rate constants were related to the light intensity (power generated by the light sensor) via a second-order polynomial regression and the model was validated experimentally (Fig. 9A).

An important assumption made for the model is that the light was homogeneously irradiating the reactor channels, justified by the light guiding and the small dimensions of the channel design. For the model to reflect its physical counterpart, the simulated control system was equipped with a time delay between receiving a light signal and the control action that altered the flow rate. This time delay was set to $0.5 \mathrm{~s}$, as determined for the experimental setup. The transient model was then subjected to a rectangular cyclic function, varying the light sensor output between 0.48 and $0.01 \mathrm{~W}$ every $20 \mathrm{~s}$, for a duration of $200 \mathrm{~s}$. This simulation was done for both a setup with and without a control system, to highlight the effect of the varying flow rate (Fig. 9B). The target conversion of $90 \%$ was consistently maintained for the control-enabled system, whereas the non-controlled simulation conversion fluctuated greatly. To test the limits of the real-time applicability of the control system, the time delay was varied $(0.5,1$, 5 and $10 \mathrm{~s}$ ), which resulted in no discernible differences between the two shortest delays, but significant differences were found for the longer time delays. In addition to rectangular functions, triangular and sinusoidal functions were also applied, since gradual variations in light intensity represent actual outdoor operation more realistically. As expected, this resulted in less drastically fluctuating conversions for the longer time delays than found for the rectangular function. These simulations showed the importance of minimizing the time delay between signal and control action when using this feedforward control system.
A

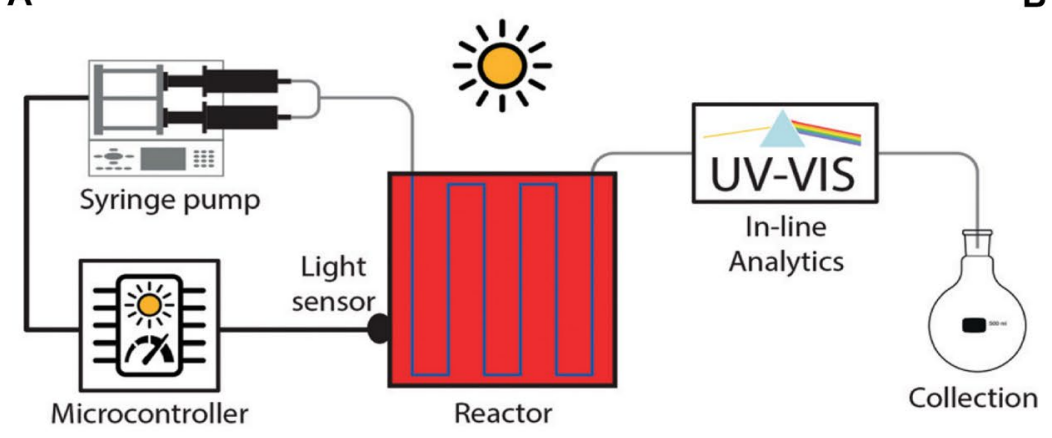

B

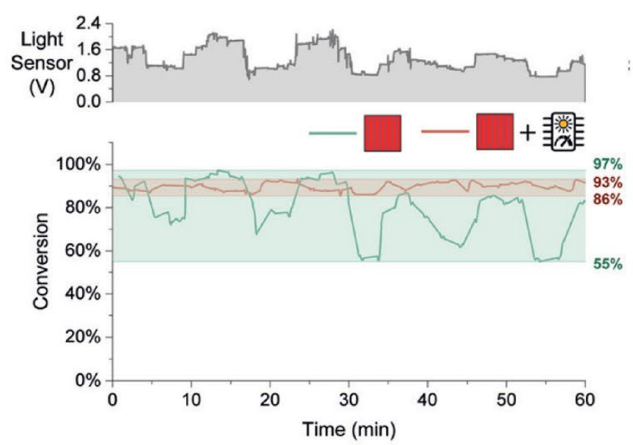

Fig. 8 A Schematic representation of the feedforward controlled LSC-PM system. B Conversion profile under fluctuating solar irradiation with and without control system. Reprinted from [70] 

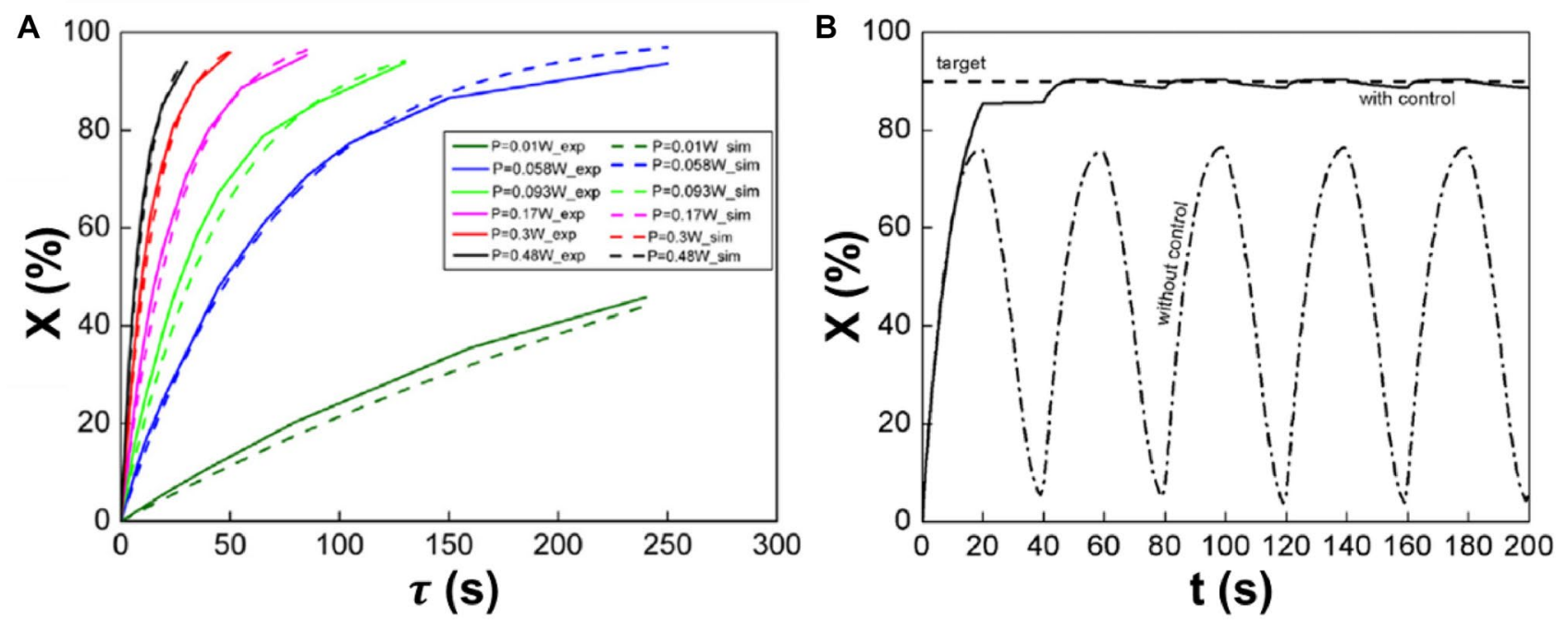

Fig. 9 Conversions for the photochemical oxidation of DPA. A Simulated (sim) and experimental (exp) steady state conversions for varying light intensity and residence times. B Simulation results of the reactor with and without control: light intensity cycled with a rectangular function between 0.48 and $0.01 \mathrm{~W}$ every $20 \mathrm{~s}$. Reprinted from [71]

\subsection{Towards an off-grid solar-powered autonomous chemical mini-plant}

With this high-efficiency LSC-PM design controlled by the feedforward system, we aspired to take the next step and designed a self-sufficient system operated away from the electric grid. This novel device was engineered by altering the previous construction process of the PMMA based LSC-PM. By doing so, wider internal diameter capillaries (increase from 0.75 to $1.6 \mathrm{~mm}$ ) could be used, increasing the internal volume of the reactor from $1.6 \mathrm{~mL}$ to $15 \mathrm{~mL}$ (Fig. 10, left) [72].

As the red luminescent panel gathers photons only up to $\sim 600 \mathrm{~nm}$, [57] the transmitted fraction of incident photons (Fig. 4B, C) can be used by a solar panel placed directly behind the LSC-PM to produce electricity. This electricity can be used to power pumps, mass flow controllers and the control system (Fig. 10, right). To compensate the fluctuations in the electrical output under a fluctuating weather, a battery is used as a buffer. The battery stores the excess of electricity produced during periods of high light intensity and compensate subsequently the lack of energy generation during less sunny periods.

Having such an independent mini-plant system detaches the photochemical reactor from the electricity grid and allows it to be deployed at any location where such a production unit is needed. Distributing the manufacturing process allows a production onsite and on-demand of unstable and toxic chemicals [73]. However, the LSCs gather both direct and diffuse light, the optimal positioning can differ from a standard photovoltaic cell. To investigate the effect of the tilt angle of the LSC-PM on the annual performance of the system, ray-tracing simulations were performed to determine the relative yearly performance depending on this tilt angle (Fig. 11A). The effect of this tilt angle on the daily and annual performance of the system is shown in Fig. 11A,
Fig. 10 Left: scaled up PMMA based LSC-PM as the key part of this solar mini-plant. Right: mini-plant system ready to perform the photooxidation of methionine to methionine sulfoxide. Adapted from [72]

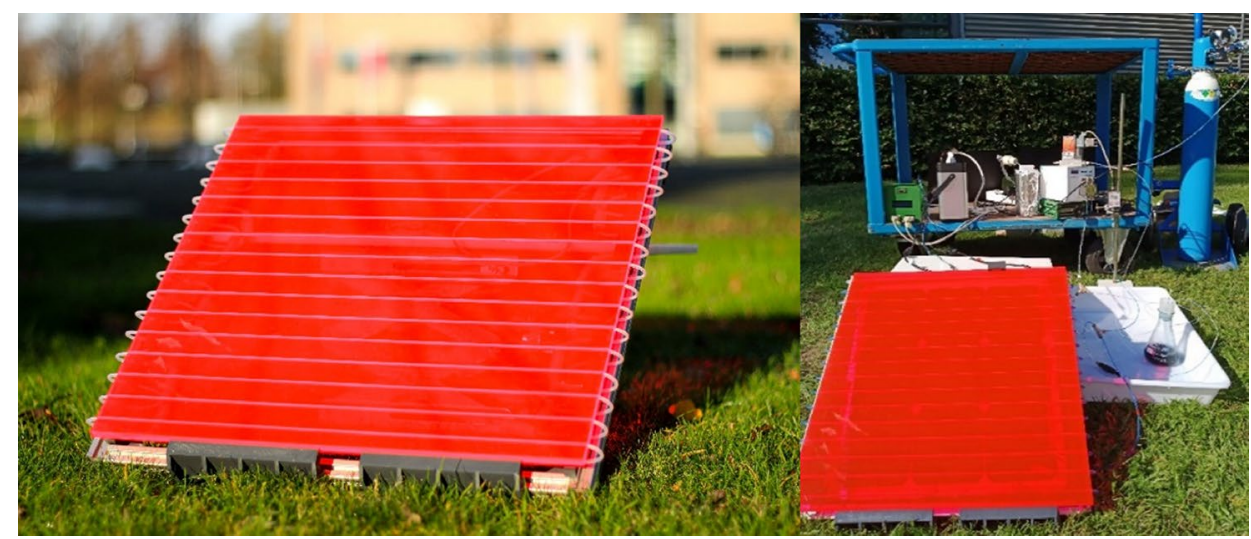


A

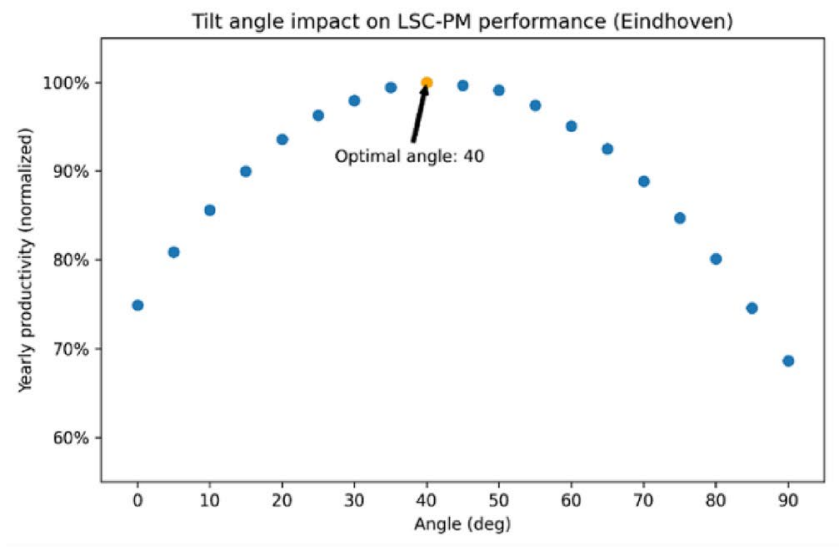

B

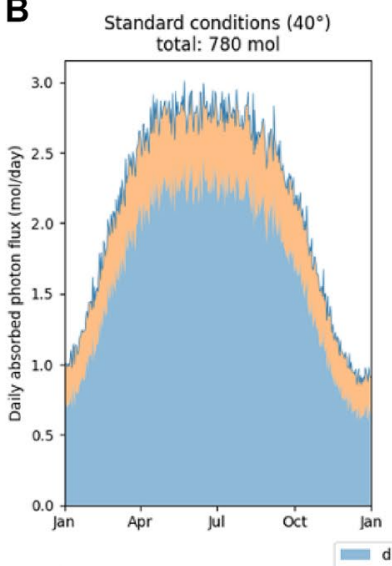

C

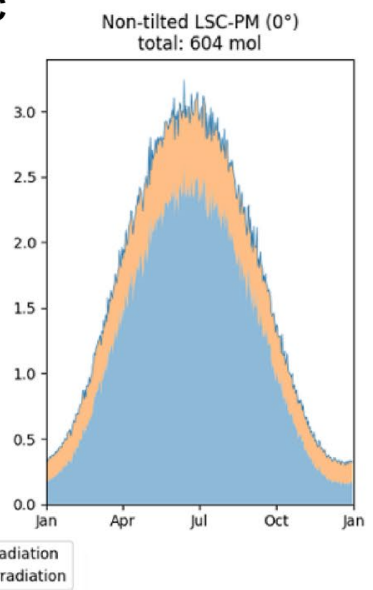

Fig. 11 A Simulated optimal tilt angle for the LSC-PM in Eindhoven. Simulated number of photons absorbed by the LSC-PM at the optimal tilt angle B and non-tilted C, in Eindhoven for the year 2021. Both the direct and diffuse contributions are shown. Adapted from [72]

B. Tilting the LSC-PM at the optimal angle introduces additional day-to-day production stability and increases the total yearly light-harvesting performance. Through additional simulations, the expected optimal tilt angle and performance of such a platform has been investigated for various locations to show that this modular production system can perform at various latitudes.

\section{Outlook}

In this account, we described our efforts towards the development of the Luminescent Solar Concentrator-based PhotoMicroreactor (LSC-PM) and its application in the solardriven synthesis of organic molecules. The use of these conceptually new photomicroreactors allowed transforming solar energy to a concentrated and wavelength-shifted irradiation which matches the absorption characteristics of the photocatalyst. Consequently, LSC-based photomicroreactors provide increased photon fluxes and higher photonic efficiencies with solar light as the sole energy source.

With the introduction of the automated LSC-PMs and the self-sufficient, carbon-neutral mini-plant design, the only source of external energy required to run these autonomous platforms is the sun. This paves the way for the platform to be used at remote and otherwise unattainable locations, e.g. for the local production of drugs with a short shelf-life or to address humanitarian needs, where fast action is often required. Of special interest could also be the application of solar photochemistry on other planets or in outer space, where solar energy can still be efficiently utilized. At such challenging locations, a small self-sufficient device could deliver varieties of fine chemicals to the operators.
As discussed in this review, to intensify photochemical reactions in LSC-PM devices, different organic dyes can be introduced into the PMMA waveguide material to target specific wavelengths through down-conversion of incident light. The realized improvement this brought about for the blue reactor, in comparison to its red and green counterparts, was limited due to the small UV-fraction of solar light on Earth, where the atmosphere shields us from most harmful UV-B and UV-C irradiation. In contrast, outer-space applications of the LSC-PMs could harness this irradiation because of the absence of this absorbing atmosphere.

Even though the tunability of the targeted wavelength by choosing another dye might seem ideal, the current LSC-PM design does not allow interchangeability of the dye, a feature the Fluorescent Fluid Photochemical Microreactor design does display. In practice, this means that a dedicated reactor must be manufactured for each set of photocatalysts within a certain absorption band. However, it is our opinion that the cheap nature of the LSC-PM material provides decisive economic advantages.

Furthermore, due to their appealing colours, LSC-based photomicroreactors can also be used as structural design elements in the construction of chemical plants. In combination with solar activation, such initiatives will help to alter the public (and often negative) image of chemistry and to make chemical plants more appealing and sustainable.

Finally, with their ability to harvest both direct and diffuse sunlight, the next generations of LSC-PMs have a bright future. Their widespread use in the chemical industry could lead to greener and more sustainable chemical processes using solar energy as the sole source of clean energy.

Acknowledgements T.M.M., S.D.A.Z. and T.N. would like to thank the European Union's Horizon 2020 research and innovation program 
for generous research funding (FlowPhotoChem, grant number 862453).

\section{Declarations}

Conflict of interest There are no conflicts of interest to declare.

Open Access This article is licensed under a Creative Commons Attribution 4.0 International License, which permits use, sharing, adaptation, distribution and reproduction in any medium or format, as long as you give appropriate credit to the original author(s) and the source, provide a link to the Creative Commons licence, and indicate if changes were made. The images or other third party material in this article are included in the article's Creative Commons licence, unless indicated otherwise in a credit line to the material. If material is not included in the article's Creative Commons licence and your intended use is not permitted by statutory regulation or exceeds the permitted use, you will need to obtain permission directly from the copyright holder. To view a copy of this licence, visit http://creativecommons.org/licenses/by/4.0/.

\section{References}

1. Draper, J. W. (1878). Scientific memoirs; Being experimental contributions to a knowledge of radiant energy. Harper \& Brothers.

2. Albini, A. (2016). Photochemistry (pp. 9-40). Springer.

3. Reischauer, S., \& Pieber, B. (2021). Emerging concepts in photocatalytic organic synthesis. iScience, 24, 102209. https://doi.org/ 10.1016/j.isci.2021.102209

4. Bottecchia, C., \& Noël, T. (2019). Photocatalytic modification of amino acids, peptides, and proteins. Chemistry-A European Journal, 25, 26-42. https://doi.org/10.1002/chem.201803074

5. König, B. (2017). Photocatalysis in organic synthesis-past, present, and future. European Journal of Organic Chemistry, 2017, 1979-1981. https://doi.org/10.1002/ejoc.201700420

6. Beatty, J. W., Douglas, J. J., Miller, R., McAtee, R. C., Cole, K. P., \& Stephenson, C. R. J. J. (2016). Photochemical perfluoroalkylation with pyridine $\mathrm{N}$-oxides: mechanistic insights and performance on a kilogram scale. Chem, 1, 456-472. https://doi.org/ 10.1016/j.chempr.2016.08.002

7. Corrigan, N., Shanmugam, S., Xu, J., \& Boyer, C. (2016). Photocatalysis in organic and polymer synthesis. Chemical Society Reviews, 45, 6165-6212. https://doi.org/10.1039/C6CS00185H

8. Narayanam, J. M. R., \& Stephenson, C. R. J. (2011). Visible light photoredox catalysis: Applications in organic synthesis. Chemical Society Reviews, 40, 102-113. https://doi.org/10.1039/B913880N

9. Khanh, T. Q., Bodrogi, P., Vinh, Q. T., \& Winkler, H. (2014). LED lighting technology and perception. Wiley-VCH Verlag $\mathrm{GmbH} \&$ Co. KGaA.

10. Cambié, D., Bottecchia, C., Straathof, N. J. W., Hessel, V., \& Noël, T. (2016). Applications of continuous-flow photochemistry in organic synthesis. Material Science, and Water Treatment, Chemical Reviews, 116, 10276-10341. https://doi.org/10.1021/ acs.chemrev.5b00707

11. Buglioni, L., Raymenants, F., Slattery, A., Zondag, S. D. A., \& Noël, T. (2021). Technological innovations in photochemistry for organic synthesis: flow chemistry, high-throughput experimentation, scale-up, and photoelectrochemistry. Chemical Reviews. https://doi.org/10.1021/acs.chemrev.1c00332

12. Sambiagio, C., \& Noël, T. (2020). Flow photochemistry: Shine some light on those tubes! Trends in Chemistry, 2, 92-106. https:// doi.org/10.1016/j.trechm.2019.09.003
13. Donnelly, K., \& Baumann, M. (2021). Scalability of photochemical reactions in continuous flow mode. Journal of Flow Chemistry. https://doi.org/10.1007/s41981-021-00168-z

14. Rehm, T. H. (2020). Reactor technology concepts for flow photochemistry. ChemPhotoChem, 4, 235-254. https://doi.org/10.1002/ cptc. 201900247

15. Williams, J. D., \& Kappe, C. O. (2020). Recent advances toward sustainable flow photochemistry. Current Opinion in Green and Sustainable Chemistry, 25, 100351. https://doi.org/10.1016/j. cogsc.2020.05.001

16. Noël, T. (2017). A personal perspective on the future of flow photochemistry. Journal of Flow Chemistry, 7, 87-93. https://doi.org/ 10.1556/1846.2017.00022

17. Kärkäs, M. D., Porco, J. A., \& Stephenson, C. R. J. J. (2016). Photochemical approaches to complex chemotypes: applications in natural product synthesis. Chemical Reviews, 116, 9683-9747. https://doi.org/10.1021/acs.chemrev.5b00760

18. Bach, T., \& Hehn, J. P. (2011). Photochemical reactions as key steps in natural product synthesis. Angewandte Chemie-International Edition, 50, 1000-1045. https://doi.org/10.1002/anie. 201002845

19. Pitre, S. P., \& Overman, L. E. (2021). Strategic use of visiblelight photoredox catalysis in natural product synthesis. Chemical Reviews. https://doi.org/10.1021/acs.chemrev.1c00247

20. Obama, B. (2017). The irreversible momentum of clean energy. Science, 355, 126-129. https://doi.org/10.1126/science.aam62 84

21. Anastas, P. T., \& Warner, J. C. (1998). Green chemistry: Theory and practice. Oxford University Press.

22. Manahan, S. E. (2005). Green Chemistry and the Ten Commandments of Sustainability. ChemChar Research. ISBN 9780615433837

23. Michelin, C., \& Hoffmann, N. (2018). Photocatalysis applied to organic synthesis-a green chemistry approach. Current Opinion in Green and Sustainable Chemistry, 10, 40-45. https://doi.org/ 10.1016/j.cogsc.2018.02.009

24. Crisenza, G. E. M., \& Melchiorre, P. (2020). Chemistry glows green with photoredox catalysis. Nature Communications, 11, 8-11. https://doi.org/10.1038/s41467-019-13887-8

25. Ravelli, D., Dondi, D., Fagnoni, M., \& Albini, A. (2009). Photocatalysis. A multi-faceted concept for green chemistry. Chemical Society Reviews, 38, 1999-2011. https://doi.org/10.1039/b7147 $86 \mathrm{~b}$

26. Albini, A., \& Fagnoni, M. (2004). Green chemistry and photochemistry were born at the same time. Green Chemistry, 6, 1-6. https://doi.org/10.1039/b309592d

27. Douglas, J. J., Sevrin, M. J., \& Stephenson, C. R. J. J. (2016). Visible light photocatalysis: applications and new disconnections in the synthesis of pharmaceutical agents. Organic Process Research \& Development, 20, 1134-1147. https://doi.org/10.1021/acs.oprd. $6 \mathrm{~b} 00125$

28. Staveness, D., Bosque, I., \& Stephenson, C. R. J. (2016). Free radical chemistry enabled by visible light-induced electron transfer. Accounts of Chemical Research, 49, 2295-2306. https://doi. org/10.1021/acs.accounts.6b00270

29. Balzani, V., Credi, A., \& Venturi, M. (2008). Photochemical conversion of solar energy. ChemSusChem, 1, 26-58. https://doi.org/ $10.1002 /$ cssc. 200700087

30. Stankiewicz, A. (2006). Energy matters: Alternative sources and forms of energy for intensification of chemical and biochemical processes. Chemical Engineering Research and Design, 84, 511-521. https://doi.org/10.1205/cherd.05214

31. Oelgemöller, M. (2016). Solar photochemical synthesis: from the beginnings of organic photochemistry to the solar manufacturing of commodity chemicals. Chemical Reviews, 116, 9664-9682. https://doi.org/10.1021/acs.chemrev.5b00720 
32. Cambié, D., \& Noël, T. (2018). Solar photochemistry in flow. Topics in Current Chemistry, 376, 45. https://doi.org/10.1007/ s41061-018-0223-2

33. Malato, S., Blanco, J., Vidal, A., \& Richter, C. (2002). Photocatalysis with solar energy at a pilot-plant scale: An overview. Applied Catalysis B: Environmental, 37, 1-15. https://doi.org/10. 1016/S0926-3373(01)00315-0

34. Fendrich, M., Quaranta, A., Orlandi, M., Bettonte, M., \& Miotello, A. (2018). Solar concentration for wastewaters remediation: A review of materials and technologies. Applied Sciences, 9, 118. https://doi.org/10.3390/app9010118

35. Bahnemann, D. (2004). Photocatalytic water treatment: Solar energy applications. Solar Energy, 77, 445-459. https://doi.org/ 10.1016/j.solener.2004.03.031

36. Ajona, J. I., \& Vidal, A. (2000). The use of CPC collectors for detoxification of contaminated water: Design, construction and preliminary results. Solar Energy, 68, 109-120. https://doi.org/ 10.1016/S0038-092X(99)00047-X

37. Tanveer, M., \& Tezcanli Guyer, G. (2013). Solar assisted photo degradation of wastewater by compound parabolic collectors: Review of design and operational parameters. Renewable and Sustainable Energy Reviews, 24, 534-543. https://doi.org/10.1016/j. rser.2013.03.053

38. Fernández-García, A., Zarza, E., Valenzuela, L., \& Pérez, M. (2010). Parabolic-trough solar collectors and their applications. Renewable and Sustainable Energy Reviews, 14, 1695-1721. https://doi.org/10.1016/j.rser.2010.03.012

39. Jung, C., Funken, K.-H., \& Ortner, J. (2005). PROPHIS: Parabolic trough-facility for organic photochemical syntheses in sunlight. Photochemical \& Photobiological Sciences, 4, 409. https://doi. org/10.1039/b500294j

40. Alp, S., Ertekin, K., Horn, M., \& Icli, S. (2004). Photostability studies of thermomesomorphic derivatives of 2,5-dihydropyrrolo[3,4-c]pyrrole-1,4-dione. Dyes and Pigments, 60, 103-110. https://doi.org/10.1016/S0143-7208(03)00143-8

41. Neumann, A., \& Groer, U. (1996). Experimenting with concentrated sunlight using the DLR solar furnace. Solar Energy, 58, 181-190. https://doi.org/10.1016/S0038-092X(96)00079-5

42. Flamant, G., Luxembourg, D., Robert, J. F., \& Laplaze, D. (2004). Optimizing fullerene synthesis in a $50 \mathrm{~kW}$ solar reactor. Solar Energy, 77, 73-80. https://doi.org/10.1016/j.solener.2004.03.001

43. Debije, M. G., \& Verbunt, P. P. C. (2012). Thirty years of luminescent solar concentrator research: Solar energy for the built environment. Advanced Energy Materials, 2, 12-35. https://doi. org/10.1002/aenm.201100554

44. Batchelder, J. S., Zewai, A. H., \& Cole, T. (1979). Luminescent solar concentrators 1: Theory of operation and techniques for performance evaluation. Applied Optics, 18, 3090. https://doi.org/10. 1364/ao.18.003090

45. Swartz, B. A., Cole, T., \& Zewail, A. H. (1977). Photon trapping and energy transfer in multiple-dye plastic matrices: An efficient solar-energy concentrator. Optics Letters, 1, 73. https://doi.org/ 10.1364/ol.1.000073

46. Weber, W. H., \& Lambe, J. (1976). Luminescent greenhouse collector for solar radiation. Applied Optics, 15, 2299. https://doi.org/ 10.1364/ao.15.002299

47. Sol, J. A. H. P., Timmermans, G. H., van Breugel, A. J., Schenning, A. P. H. J., \& Debije, M. G. (2018). Multistate luminescent solar concentrator "smart" windows. Advanced Energy Materials. https://doi.org/10.1002/aenm.201702922

48. Kanellis, M., de Jong, M. M., Slooff, L., \& Debije, M. G. (2017). The solar noise barrier project: 1 . Effect of incident light orientation on the performance of a large-scale luminescent solar concentrator noise barrier. Renewable Energy, 103, 647-652. https:// doi.org/10.1016/j.renene.2016.10.078
49. Reinders, A., Kishore, R., Slooff, L., \& Eggink, W. (2018). Luminescent solar concentrator photovoltaic designs. Japanese Journal of Applied Physics, 57, 08RD10. https://doi.org/10.7567/JJAP.57. 08RD10

50. Corrado, C., Leow, S. W., Osborn, M., Carbone, I., Hellier, K., Short, M., Alers, G., \& Carter, S. A. (2016). Power generation study of luminescent solar concentrator greenhouse. Journal of Renewable and Sustainable Energy, 8, 043502. https://doi.org/10. 1063/1.4958735

51. Papakonstantinou, I., Portnoi, M., \& Debije, M. G. (2021). The hidden potential of luminescent solar concentrators. Advanced Energy Materials, 11, 2002883. https://doi.org/10.1002/aenm. 202002883

52. Hoelen, C. G. A., Benoy, D. A., Cornelissen, H. J., Vdovin, A. V., \& Bruls, D. (2019). High brightness light sources based on LD-pumped luminescent converters and LED-pumped luminescent concentrators. In M. Strassburg, J. K. Kim, \& M. R. Krames (Eds.), Light-emitting devices, materials, and applications (Vol. 1094015, p. 41). SPIE.https://doi.org/10.1117/12.2511511

53. Amarnath, K., Bennett, D. I. G., Schneider, A. R., \& Fleming, G. R. (2016). Multiscale model of light harvesting by photosystem II in plants. Proceedings of the National Academy of Sciences of the United States of America, 113, 1156-1161. https://doi.org/10. 1073/pnas. 1524999113

54. Tummeltshammer, C., Taylor, A., Kenyon, A. J., \& Papakonstantinou, I. (2016). Losses in luminescent solar concentrators unveiled. Solar Energy Materials and Solar Cells, 144, 40-47. https://doi. org/10.1016/j.solmat.2015.08.008

55. Haas, C. P., Roider, T., Hoffmann, R. W., \& Tallarek, U. (2019). Light as a reaction parameter-systematic wavelength screening in photochemical synthesis. Reaction Chemistry \& Engineering, 4, 1912-1916. https://doi.org/10.1039/c9re00339h

56. Amos, S. G. E., Garreau, M., Buzzetti, L., \& Waser, J. (2020). Photocatalysis with organic dyes: Facile access to reactive intermediates for synthesis. Beilstein Journal of Organic Chemistry, 16, 1163-1187. https://doi.org/10.3762/bjoc.16.103

57. Cambié, D., Zhao, F., Hessel, V., Debije, M. G., \& Noël, T. (2017). A leaf-inspired luminescent solar concentrator for energyefficient continuous-flow photochemistry. Angewandte ChemieInternational Edition, 56, 1050-1054. https://doi.org/10.1002/ anie. 201611101

58. Cambié, D., Zhao, F., Hessel, V., Debije, M. G., \& Noël, T. (2017). Every photon counts: Understanding and optimizing photon paths in luminescent solar concentrator-based photomicroreactors (LSC-PMs). Reaction Chemistry and Engineering, 2, 561-566. https://doi.org/10.1039/c7re00077d

59. Dong, Z., Wen, Z., Zhao, F., Kuhn, S., \& Noël, T. (2021). Scaleup of micro- and milli-reactors: An overview of strategies, design principles and applications. Chemical Engineering Science: X, 10, 100097. https://doi.org/10.1016/j.cesx.2021.100097

60. Zhao, F., Cambié, D., Janse, J., Wieland, E. W., Kuijpers, K. P. L., Hessel, V., Debije, M. G., \& Noël, T. (2018). Scale-up of a luminescent solar concentrator-based photomicroreactor via numbering-up. ACS Sustainable Chemistry \& Engineering, 6, 422-429. https://doi.org/10.1021/acssuschemeng.7b02687

61. Zhang, L., Zhu, Z., Liu, B., Li, C., Yu, Y., Tao, S., \& Li, T. (2019). Fluorescent fluid in 3D-printed microreactors for the acceleration of photocatalytic reactions. Advanced Science, 6, 1-6. https://doi. org/10.1002/advs.201900583

62. Zhu, Z., Yang, L., Yu, Y., Zhang, L., \& Tao, S. (2020). Scaleup design of a fluorescent fluid photochemical microreactor by 3D printing. ACS Omega, 5, 7666-7674. https://doi.org/10.1021/ acsomega.0c00511

63. McDonald, J. C., Duffy, D. C., Anderson, J. R., Chiu, D. T., Wu, H., Schueller, O. J. A., \& Whitesides, G. M. (2000). Fabrication of microfluidic systems in poly(dimethylsiloxane). Electrophoresis, 
21, 27-40. https://doi.org/10.1002/(SICI)1522-2683(20000101) 21:1\%3c27::AID-ELPS27\%3e3.0.CO;2-C

64. Mori, R., Iasilli, G., Lessi, M., Muñoz-García, A. B., Pavone, M., Bellina, F., \& Pucci, A. (2018). Luminescent solar concentrators based on PMMA films obtained from a red-emitting ATRP initiator. Polymer Chemistry, 9, 1168-1177. https://doi.org/10.1039/ c7py01933e

65. Meinardi, F., Colombo, A., Velizhanin, K. A., Simonutti, R., Lorenzon, M., Beverina, L., Viswanatha, R., Klimov, V. I., \& Brovelli, S. (2014). Large-area luminescent solar concentrators based on stokes-shift-engineered nanocrystals in a mass-polymerized PMMA matrix. Nature Photonics, 8, 392-399. https://doi.org/10. 1038/nphoton.2014.54

66. J. S. Batchelder, A. H. Zewail and T. Cole, in Proceedings of the Society of Photo-Optical Instrumentation Engineers, ed. S. K. Deb, 1980, vol. 248, pp. 105-108.

67. Cambié, D., Dobbelaar, J., Riente, P., Vanderspikken, J., Shen, C., Seeberger, P. H., Gilmore, K., Debije, M. G., \& Noël, T. (2019). Energy-efficient solar photochemistry with luminescent solar concentrator based photomicroreactors. Angewandte Chemie International Edition, 58, 14374-14378. https://doi.org/10.1002/anie. 201908553

68. van Sark, W. G. J. H. M., Barnham, K. W. J., Slooff, L. H., Chatten, A. J., Büchtemann, A., Meyer, A., McCormack, S. J., Koole, R., Farrell, D. J., Bose, R., Bende, E. E., Burgers, A. R., Budel, T., Quilitz, J., Kennedy, M., Meyer, T., Donegá, C. D. M., Meijerink, A., \& Vanmaekelbergh, D. (2008). Luminescent solar concentrators-a review of recent results. Optics Express, 16, 21773. https://doi.org/10.1364/oe.16.021773

69. Zhao, F., Chen, Z., Fan, W., Dou, J., Li, L., \& Guo, X. (2020). Reactor optimization and process intensification of photocatalysis for capillary-based PMMA LSC-photomicroreactors. Chemical Engineering Journal, 389, 124409. https://doi.org/10.1016/j.cej. 2020.124409

70. Zhao, F., Cambié, D., Hessel, V., Debije, M. G., \& Noël, T. (2018). Real-time reaction control for solar production of chemicals under fluctuating irradiance. Green Chemistry, 20, 2459-2464. https:// doi.org/10.1039/c8gc00613j

71. de Oliveira, G. X., Lira, J. O. B., Cambié, D., Noël, T., Riella, H. G., Padoin, N., \& Soares, C. (2020). CFD analysis of a luminescent solar concentrator-based photomicroreactor (LSC-PM) with feedforward control applied to the synthesis of chemicals under fluctuating light intensity. Chemical Engineering Research and Design, 153, 626-634. https://doi.org/10.1016/j.cherd.2019.10. 047

72. Masson, T. M., Zondag, S. D. A., Kuijpers, K. P. L., Cambié, D., Debije M. G., \& Noël, T. Development of an off-grid solar-powered autonomous chemical mini-plant for producing fine chemicals. Under submission. https://doi.org/10.1002/cssc.202102011

73. Dallinger, D., Gutmann, B., \& Kappe, C. O. (2020). The concept of chemical generators: on-site on-demand production of hazardous reagents in continuous flow. Accounts of Chemical Research, 53, 1330-1341. https://doi.org/10.1021/acs.accounts.0c00199

\section{Authors and Affiliations}

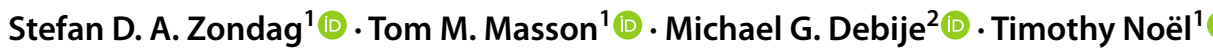

Timothy Noël

t.noel@uva.nl

1 Flow Chemistry Group, Van 't Hoff Institute for Molecular Sciences (HIMS), Universiteit Van Amsterdam (UvA), Science Park 904, 1098 XH Amsterdam, The Netherlands
2 Department of Chemical Engineering and Chemistry, Stimuli-Responsive Functional Materials and Devices, Eindhoven University of Technology, Groene Loper 3, Bldg 14 - Helix, 5600 MB Eindhoven, The Netherlands 